\title{
Forced exercise activates the NrF2 pathway in the striatum and ameliorates motor and behavioral manifestations of Parkinson's disease in rotenone-treated rats
}

\author{
Dina M. Monir ${ }^{1 \dagger}$, Motamed E. Mahmoud ${ }^{2 *}$, Omyma G. Ahmed ${ }^{3}$, Ibrahim F. Rehan ${ }^{4}$ \\ and Amany Abdelrahman ${ }^{* *}$ (i)
}

\begin{abstract}
Background: Parkinson's disease (PD) is a common neurodegenerative disorder characterized by progressive loss of nigrostriatal dopaminergic neurons leading to dopamine depletion and problems of movement, emotions, and cognition. While the pathogenesis of PD is not clear, damage of dopaminergic neurons by oxygen-derived free radicals is considered an important contributing mechanism. This study aimed to evaluate the role of treadmill exercise in male Wister rats as a single treatment and as an aid-therapy with L-dopa for rotenone-induced PD. To study the role of the Nrf2- ARE pathway as a mechanism involved in exercise-associated improvement in rotenone-induced PD in rats.

Method: Animals were divided into 5 groups, (Control, rotenone, rotenonelexercise, rotenonelL-dopa, and rotenonelexercise $\backslash$ - -dopa (combination)groups). After the PD induction, rats in the rotenonelexercise and combination groups were daily treadmill exercised for 4 weeks.

Results: Treadmill exercise significantly improved behavioral and motor aspects of rotenone-induced PD. When treadmill exercise was introduced as a single intervention, it amended most behavioral aspects of PD, gait fully corrected, short-term memory, and motor coordination. Where L-dopa corrected locomotor activity and motor coordination but failed to improve short-term memory and only partially corrected the gait of rotenone-treated rats. When treadmill exercise was combined with L-dopa, all features of PD were corrected. It was found that exercise upregulated some of its associative genes to Nrf2 pathways such as TFAM, Nrf2 and NQO.1 mRNA expression.
\end{abstract}

Conclusion: This study suggests that forced exercise improved parkinsonian like features by activating the Nrf2 pathway.

Keywords: Parkinson, Rotenone, Behavioral tests, Exercise, Nrf2. TFAM, Noq1

*Correspondence: motamed71111@gmail.com; amany_abdelhameed@med. sohag.edu.eg

†Dina M. Monir and Motamed E. Mahmoud are equally contributed ${ }^{1}$ Department of Physiology, Faculty of Medicine, Sohag University, Sohag 82524, Egypt

${ }^{2}$ Department of Animal Behavior and Husbandry (Genetics, Breeding, and Production), Faculty of Veterinary Medicine, Sohag University, Sohag 82524, Egypt

Full list of author information is available at the end of the article

\section{Background}

Parkinson's disease (PD) is a common neurodegenerative disorder characterized by persistent loss of nigrostriatal dopaminergic neurons leading to depletion of dopamine and consequent problems of movement, emotions, and cognition. While many factors contribute to the pathogenesis of PD, damage of dopaminergic neurons by oxygen-derived free radicals is considered an important

c) The Author(s) 2020. This article is licensed under a Creative Commons Attribution 4.0 International License, which permits use, sharing, adaptation, distribution and reproduction in any medium or format, as long as you give appropriate credit to the original author(s) and the source, provide a link to the Creative Commons licence, and indicate if changes were made. The images or other third party material in this article are included in the article's Creative Commons licence, unless indicated otherwise in a credit line to the material. If material is not included in the article's Creative Commons licence and your intended use is not permitted by statutory regulation or exceeds the permitted use, you will need to obtain permission directly from the copyright holder. To view a copy of this licence, visit http://creativeco mmons.org/licenses/by/4.0/. The Creative Commons Public Domain Dedication waiver (http://creativecommons.org/publicdomain/ zero/1.0/) applies to the data made available in this article, unless otherwise stated in a credit line to the data. 
contributing mechanism [1, 2]. Rotenone is a potent inhibitor of complex I (NADH: ubiquinone oxidoreductase) of the mitochondrial electron transport chain. This allows for accumulation and overproduction of reactive oxygen species (ROS) which eventually leads to cell damage $[3,4]$. Chronic rotenone exposure in rats causes both neuropathological findings and behavioral symptoms of PD [5]. The rotenone model mimics the gradual progression of PD as observed in humans. Systemic mitochondrial inhibition by rotenone leads to selective nigrostriatal degeneration [6].

Treadmill exercise is indicated as a physical therapy to improve motor symptoms in patients with PD. Exercise can improve and alleviate memory loss in elderly patients, and decrease the risk of developing PD. The neuroprotective potentials of exercise are great, but the underlying mechanisms remain a debatable issue. Evidence suggests that exercise neuroprotection is due to its neurotrophic effects, as exercise increases the availability of several neurotrophic factors [7]. Long-term exercise benefits brain functioning by increasing the blood and oxygen flow to the brain, mobilizing growth factors that promote neurogenesis and synaptic plasticity, releasing of neurotransmitters, such as dopamine (DA), noradrenaline, serotonin, and glutamate and consequently improve manifestations of the disease either at the motor or cognitive. levels in Alzheimer's animal model [8].

Exercise increases the antioxidant status in the striatum of animals and protects against neurological oxidative challenges. The nuclear factor erythroid-derived 2-like 2 (Nrf2)-antioxidant response element (ARE) signaling pathway, a major cellular defense mechanism against oxidative stress. Exercise activates $N r f 2$ in human skeletal muscles and mouse heart [9]. The Nrf2-ARE signaling pathway appears to be a strong mechanism for exercise-induced neuroprotection [10]. The activation of the $N r f 2$ gene activates genes that encode for antioxidant enzymes within the cells like heme oxygenase and NADH quinone oxidoreductase (NQO1). Also, Nrf2 activates the mitochondrial transcription factor A (TFAM) which regulates for mitochondrial DNA (mtDNA) replication [11]. Therefore, in this study, we investigated whether treadmill exercise as a single therapeutic intervention and as add-on therapy with L-dopa improve manifestations of PD in rotenone-treated rats. Also, we assessed the Nrf2 pathway as a possible mechanism activated by treadmill exercise.

\section{Materials and methods}

\section{Animals and experimental design}

Fifty-adult male Wistar rats with body weight averaged $275 \pm 25$ gm, 9 months aged; were purchased from the Faculty of Science, Sohag University, and were housed in the Medical Animal Laboratory in Sohag Faculty of Medicine. Animals were allowed free access to food and tap water. Rats were housed in standard cages, at normal light/dark cycle and room temperature. The rats were randomly divided into 5 groups $(\mathrm{n}=10$ in each group); control group, rotenone-injected group, rotenonelexercise group, rotenone $\backslash \mathrm{L}$-dopa treated-group, and combined (rotenone $\backslash$ L-dopalexercise) group. The study was approved by Research Ethics Committee considering the care and use of laboratory animals (permission number: SOH-IACUC-17050301).

\section{Induction of Parkinsonism}

Rats were subcutaneously injected with either vehicle or rotenone (R8875; 95\%, Sigma-Aldrich, USA) $2 \mathrm{mg} / \mathrm{kg}$, for 4 weeks. Rotenone solution was prepared as a $50 \times$ stock in $100 \%$ dimethylsulfoxide (DMSO) then in a mediumchain triglyceride, miglyol $812 \mathrm{~N}$ (Sigma) to obtain a final concentration of $2 \mathrm{mg} / \mathrm{mL}$ rotenone in $98 \%$ miglyol $812 \mathrm{~N}, 2 \%$ DMSO. The prepared solution was stored in an amber septa vial to be protected from light and inverted many times before each injection to eliminate the possibility of settling [12]. L-dopa (L-3, 4 dihydroxyphenylalanine methyl ester hydrochloride, (Sigma) was dissolved in normal saline and was administered at a dose $6 \mathrm{mg} / \mathrm{kg} /$ day, injected intraperitoneally for 4 weeks.

\section{Exercise protocol and treatments}

After induction of PD, rats in the exercise group were forced to run in a 3-channel treadmill (Heath Life $\mathrm{V} 4000 \mathrm{M})$. The exercise regimen continues for $30 \mathrm{~min} /$ day, 5 times a week for 4 weeks. The treadmill speed accelerates beginning with $2 \mathrm{~m} / \mathrm{min}$ during the first $5 \mathrm{~min}$, at $3 \mathrm{~m} / \mathrm{min}$ during the second $5 \mathrm{~min}$, and then at $5 \mathrm{~m} / \mathrm{min}$ for the last $20 \mathrm{~min}$ [13]. The efficiency of this exercise protocol was previously assessed by measuring the serum lactate dehydrogenase and creatine phosphokinase in a non-published experiment (Additional file 1: Fig. S1).

\section{Behavioral and motor analysis}

These tests assess motor activity, and behavior of the rats, they were performed at the end of the experiment for all groups and included;

\section{Open field test (OFT)}

OFT was performed according to the previously described method [14]. The apparatus was a squared plastic arena $(114 \times 114 \times 44$ height $\mathrm{cm})$ its floor was divided into smaller squares $\left(19 \times 19 \mathrm{~cm}^{2}\right)$ with a central square $\left(38 \times 38 \mathrm{~cm}^{2}\right)$ each rat was put gently in the center of the arena and was left for $5 \mathrm{~min}$ moving and exploring the field. A video camera was fixed at the top of the 
arena to record the activity of the rat which was scored by a specialist who was blind to the experimental groups. Each animal was then given a score for total locomotor activity; calculated as the sum number of line crosses and rears, a score for exploratory behavior; the sum of the number of central square entries and the duration of time spent in the central square, and the anxiety score is equal to the sum of urination and defecation boli [14].

\section{Object recognition test (ORT)}

ORT was performed as described by Walsh and Cummins [15]. To assess the short-term memory (STM) and longterm memory (LTM), four objects used were made of plastic material. The objects and arena were washed with a $10 \%$ ethanol solution after each trial. The training was conducted by placing each rat for $5 \mathrm{~min}$ into the open field apparatus, where two identical objects (objects A1 and A2) were put in two adjacent sides, $10 \mathrm{~cm}$ from the walls. In the STM test, a rat was given $1.5 \mathrm{~h}$ after training; the rats explored the open field for $5 \mathrm{~min}$ in the presence of one familiar (A) and one novel (B) object. LTM test was done $24 \mathrm{~h}$ after training, the same rat explored the field for $5 \mathrm{~min}$ in the presence of a familiar object $\mathrm{A}$ and a novel object $\mathrm{C}$. Exploration is defined as sniffing or touching the object with the nose and/ or forepaws. The time $(\mathrm{T})$ which is spent by each rat exploring the different objects was measured as TA1, TB, and TC. These times were used for calculation of STM $=[\mathrm{TB} /$ $(\mathrm{TA} 1+\mathrm{TB})] 100$, and $\mathrm{LTM}=[\mathrm{TC} /(\mathrm{TA} 1+\mathrm{TC})] 100$.

\section{Foot print test}

Footprint test was used to measure gait analysis by permitting rats to run in a wood corridor apparatus $\left(65 \times 5 \times 15 \mathrm{~cm}^{3}\right)$, which was lined with a pre-cut piece of white paper. Rats were trained to run to the end of the corridor by placing the rats at the far end of the corridor and encouraging them to move towards the end. The training was conducted twice for each rat until the animal could run to the end box without encouragement. For testing, the paws of the animal were painted with four non-toxic watercolors as described previously [16]. For each animal, the gait was calculated using 4 paw prints; this allowed 5 values-yield/rat; [front stride length (FSL), front stride width (FSW), hind stride length (HSL), hind stride width (HSW) and overlap (OL)] which were then averaged to provide gait measurements [15].

\section{Rota-rod test}

To assess the motor coordination of the animals, we used an accelerating Rota-rod (Harvard Apparatus, UK). The Rota-rod consisted of a suspended rod, accelerating for $60 \mathrm{~s}$, beginning from 5 rounds per minute (RPM) to reach 15 RPM, and continuing at that speed for a further $60 \mathrm{~s}$. A trial was stopped when the rats fell off the Rota-rod or after they complete $120 \mathrm{~s}$. The mean latency time of the three trials was taken. Animals were trained for five days to perform the test [17].

\section{Tissue Sampling}

After behavioral tests, the rats were anesthetized with Zoletil (1 mg $\backslash \mathrm{kg}$ i.p (Vibac Laboratories, Carros, France). Rats were transcardially perfused with $0.05 \mathrm{M}$ phosphatebuffered saline (PBS). The brain was removed, separated into right and left hemispheres, snap-frozen in liquid nitrogen, and kept for $1 \mathrm{~h}$ at $-80{ }^{\circ} \mathrm{C}$. The striatum was dissected through multiple manual coronal sections with a sharp razor blade and was collected with the help of two Dumont No. 5 forceps [18]. Samples then were stored in Eppendorf tubes at $-80{ }^{\circ} \mathrm{C}$ until further analyses.

\section{(1) RNA extraction}

Total RNA was extracted from $30 \mathrm{mg}$ of tissue samples according to manufacture instructions (RNA Extraction kit (\#K0731, Thermo Scientific, Lithuania)). They were extracted to measure Nrf2, NOQ.1, TFAM, and using housekeeping GAPDH by real-time polymerase chain reaction (real-time PCR).

\section{(2) Reverse transcription}

Extracted RNA concentration was quantified using Nanodrop spectrophotometry (Quawell 5000, USA); then 110 ng of total RNA transcribed using RNA reverse transcriptase kits ((\#K0251) (Thermo Scientific, Lithuania)). The thermal cycler was programmed at $25^{\circ} \mathrm{C}$ for $10 \mathrm{~min}$, $37^{\circ} \mathrm{C}$ for $120 \mathrm{~min}, 85^{\circ} \mathrm{C}$ for $5 \mathrm{~min}$, and $4{ }^{\circ} \mathrm{C}$ for $20 \mathrm{~h}$.

\section{(3) Real-time PCR}

Prepared cDNA, was used in the qPCR analyzer (Step One, Applied Biosystems, Singapore) using the MAXIMA SYBR Green qPCR Master Mix with the following program: 1 cycle at $95{ }^{\circ} \mathrm{C}$ for $10 \mathrm{~min} ; 40$ cycles of $95{ }^{\circ} \mathrm{C}$ for $15 \mathrm{~s}, 60{ }^{\circ} \mathrm{C}$ for $30 \mathrm{~s}$ and $72{ }^{\circ} \mathrm{C}$ for $30 \mathrm{~s}$; one cycle at $95{ }^{\circ} \mathrm{C}$ for $15 \mathrm{~s}, 60{ }^{\circ} \mathrm{C}$ for $1 \mathrm{~min}$ and $95^{\circ} \mathrm{C}$ for $15 \mathrm{~s}$. The specific primers (Table 1) of Nrf2, TFAM, NADPH dehydrogenase (NQO1) \& housekeeping GAPDH were purchased from Metabion international AG, Germany. Fold expression $\left(2^{-\Delta \Delta c t}\right)$ was calculated according to the relative expression of housekeeping gene GAPDH.

\section{(4) Tyrosine hydroxylase}

Homogenized striatum of the right hemisphere of all rat brains was used to measure the levels of tyrosine hydroxylase enzyme by ELISA (tyrosine hydroxylase $(\mathrm{TH})$ rat ELISA kits (\#:96,791) from Glory Science Co., (Ltd, China) with a detection range $0.625-20 \mathrm{ng} \backslash \mathrm{ml}$. 
Table 1 Forward and reverse primers for real time PCR

\begin{tabular}{|c|c|c|c|c|}
\hline Gene name & Forward primer & Reverse primer & Access number & References \\
\hline NRF2 & $5^{\prime}$ CACATCCAGACAGACACCAGT-3' & $5^{\prime}$ CTACAAATGGGAATGTCTCTGC-3' & NM_031789 & [19] \\
\hline TFAM & 5'AGTTCATACCTTCGATTTTC-3' & $5^{\prime}$ TGACTTGGAGTTAGCTGC-3’ & NM_031326.1 & [20] \\
\hline NQO1 & 5'CAGCGGCTCCATGTACT-3' & $5^{\prime}$ GACCTGGAAGCCACAGAAG-3' & NM_017000 & {$[19,21]$} \\
\hline GAPDH & $5^{\prime C A G G C A T A T G G T G G T C C A T A G A G-3 ' ~}$ & $5^{\prime}$ TCATGGGATCCACCTGCAGC-3' & NM_017008 & [19] \\
\hline
\end{tabular}

NRF2 nuclear factor erythroid 2 (NFE2)-related factor 2, NQO1 quinone oxidoreductase 1, TFAM Mitochondrial transcriptional factor A, GAPDH glyceraldehyde-3phosphate dehydrogenase

\section{Statistical analysis}

Statistical package for social sciences (IBM-SPSS), version 24 IBM- Chicago, USA (May 2016) was used for statistical data analysis. Data expressed as mean \pm standard deviation (SD), number, and percentage. A one-way analysis of variance (ANOVA) test was used to compare the means of the analyzed groups. Post hoc test (LSD type) was used for multiple comparisons between each group and the other. $\mathrm{P}$-value was considered significant when $\mathrm{P}<0.05$.

\section{Results}

Treadmill exercise, L-dopa and their combination improved exploration, and locomotion in rotenone-treated groups

(Fig. 1)

After 4 weeks of daily administration of rotenone, rats spent less time in locomotion and exploration of open field environment compared to the vehicle-injected group ( $p=0.00007$, Fig. 1$)$. But the anxiety scores in terms of urination and defecation times were not different between both groups. To sum, rotenone injection decreased exploration and locomotion scores in the open field test.

It was noticed that after injection of rotenone, rats practiced 5 times/week a treadmill exercise spent less time in the central arena and increased number of line crossings in the open-field test compared to the nonexercised rotenone group $(\mathrm{p}=0.0004)$. Similarly, after rotenone-administration, in rats treated with L-dopa and L-dopa co-treatment with exercise practice recovered the locomotor and exploratory activities after rotenone treatment. However, L-dopa \rotenone and the combined exercise $\backslash$ L-dopa $\backslash$ rotenone groups showed significantly higher locomotor scores than the exercisel rotenone group, $(p=0.0009)$. There was an insignificant difference regarding exploration $(p=0.50)$ in-between the three treatment groups. Also, there was no significant change concerning the anxiety score between the five groups under the study.

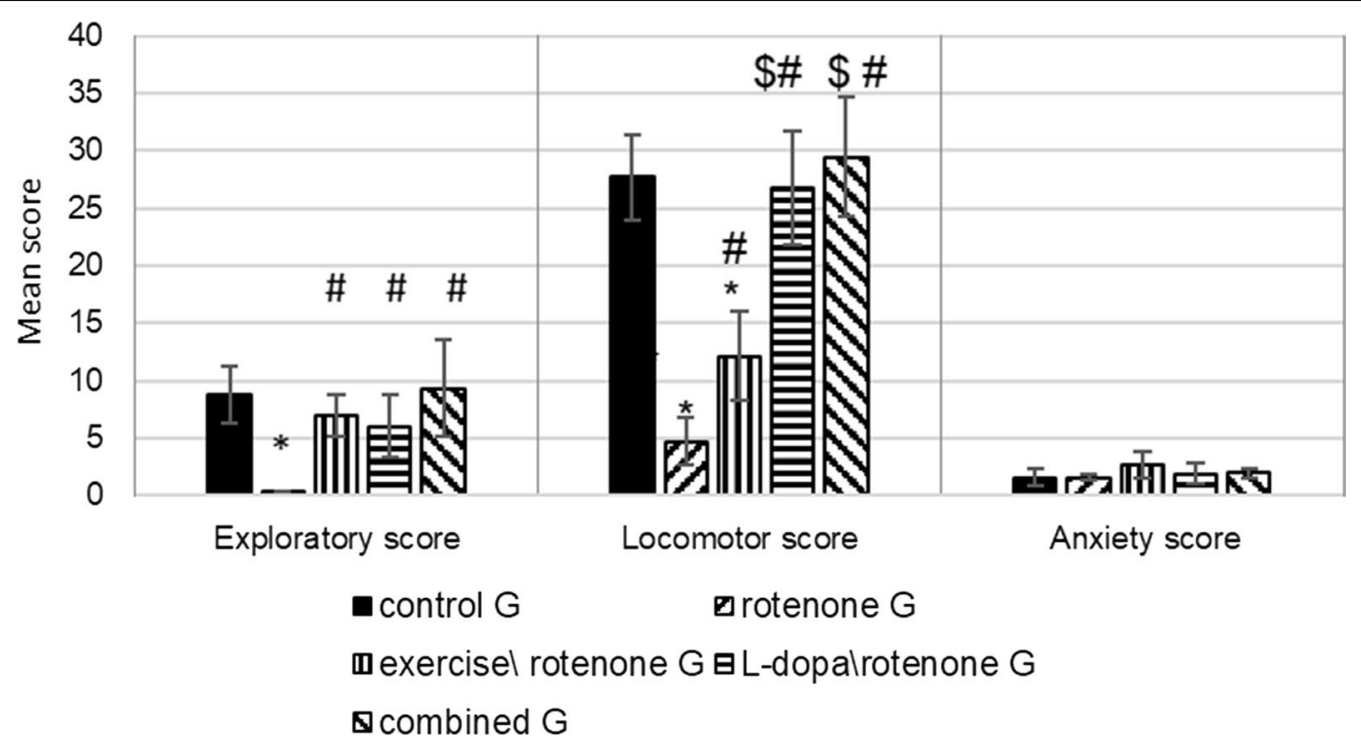

Fig. 1 Open field test effect of exercise (4 weeks treadmill), L-dopa ( $6 \mathrm{mg} \backslash \mathrm{kg} I \mathrm{P})$, and their combination on rotenone treated rats ( $2 \mathrm{mg}$ kg SC for 4 weeks). $\mathrm{N}=10$ rats Igroup. The analysis was done by ANOVA test. P-value $<0.05,{ }^{*}$ compare to control $\mathrm{G}$, \# in comparison with the rotenone $\mathrm{G}$ 
Treadmill exercise alone and in combination with L-dopa improved STM in the rotenone-treated groups (Fig. 2)

There was a significant decrease in STM of the rotenone-treated group compared to the control group $(\mathrm{p}=0.02)$. No significant difference as regard LTM in either group.

L-dopa alone didn't improve STM in the rotenone treated rats $(p=0.23)$ while, exercise alone or its combination with L-dopa has produced significant improvements in the STM in comparison with the rotenone-injected group $(\mathrm{p}=0.03)$. Meanwhile, LTM was insignificantly changed among all groups $(\mathrm{p}=0.38)$.
Treadmill exercise alone and in combination with L-dopa fully corrected the gait, while L-dopa alone caused a partial correction of gait analysis

Rotenone injection caused a significant gait impairment in comparison to the control rats in terms of increased overlap (OL) distance $(\mathrm{p}=0.001)$, shortened both stride length; hind (HSL) and front (FSL) steps, and similarly significant wide base, as detected by increased FSW and HSW ( $\mathrm{p}=0.03$, Table 2).

Treadmill exercise alone and exercise /L-dopa treatment corrected OL distance induced by rotenone injection $(p=0.001)$. Additionally, increased the FSL and

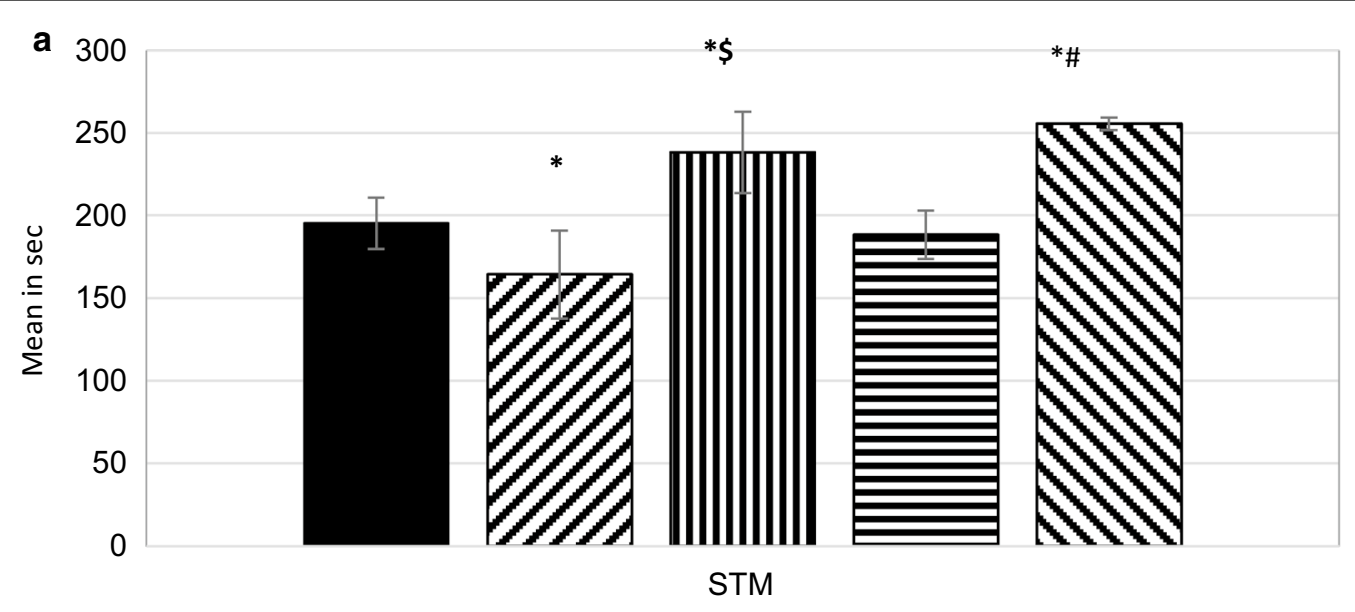

\begin{tabular}{|c|c|c|}
\hline control G & $\square$ rotenone G & m rotenonelexercise G \\
\hline
\end{tabular}

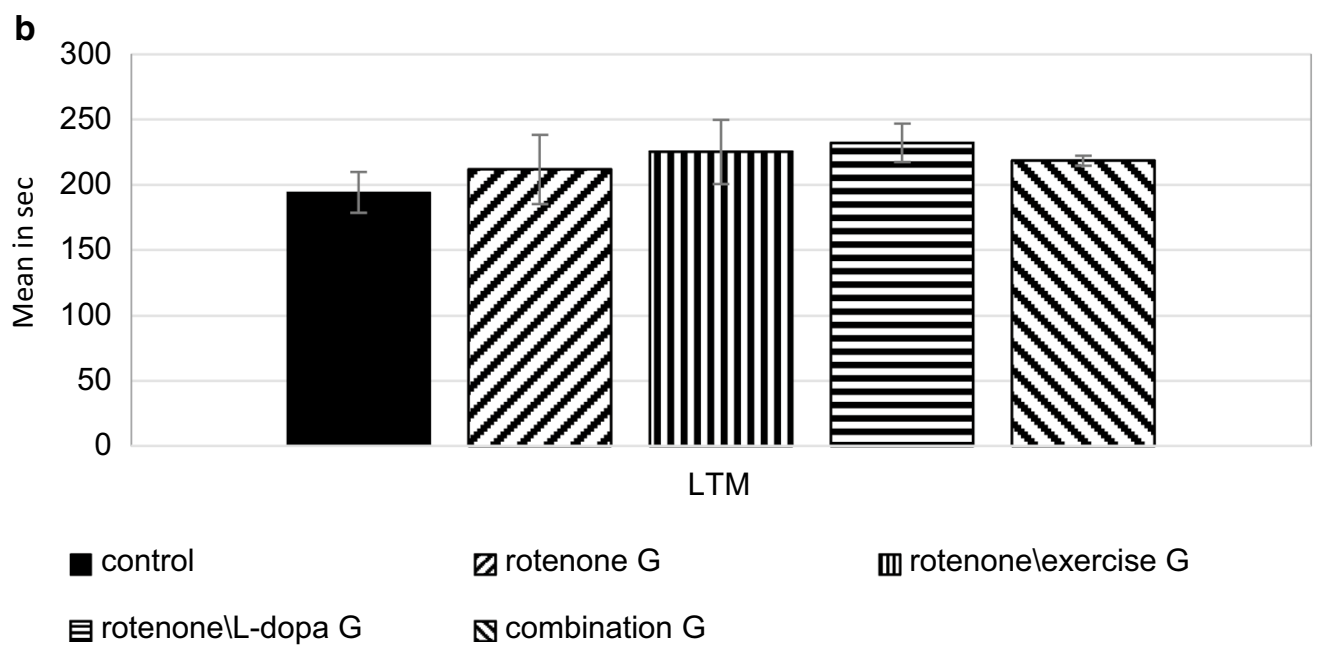

Fig. 2 Object recognition test, the effect of exercise (4 weeks treadmill), L-dopa ( $6 \mathrm{mg} \backslash \mathrm{kg} I \mathrm{P}$ ), and their combination on rotenone treated rats ( 2 mg $\backslash \mathrm{kg}$ SC for 4 weeks) on STM (Fig a) and LTM (Fig b). The analysis was done by ANOVA test. P-value is considered significant when P $<0.05$, $\mathrm{n}=10$ rat in each group. ${ }^{*}$ compare to control group, ${ }^{*}$ in comparison with the rotenone treated group. STM short term memory, LTM long term memory 
Table 2 Effects of exercise, L-dopa and their combination on gait measured by Foot print test (overlap, front stride width, front stride length, hind stride width and hind stride length in $\mathrm{cm}$ )

\begin{tabular}{|c|c|c|c|c|c|c|}
\hline Group & Control G & Rotenone G & Rotenone $\backslash$ exercise G & RotenonelL-dopa G & Combined G & $\begin{array}{l}\text { P-value } \\
\text { by ANOVA }\end{array}$ \\
\hline \multirow[t]{2}{*}{$\mathrm{OL}$} & $1.50 \pm 0.3$ & $2.10 \pm 0.45$ & $1.40 \pm 0.3$ & $1.35 \pm 0.2$ & $1.55 \pm 0.3$ & 0.0008 \\
\hline & & ${ }^{*} P=0.001$ & ${ }^{\#} P=0.001$ & $\# P=0.0001$ & ${ }^{\# P}=0.003$ & \\
\hline \multirow[t]{2}{*}{ FSW } & $4.95 \pm 1.23$ & $5.95 \pm 0.83$ & $3.40 \pm 0.99$ & $5.20 \pm 0.91$ & $4.15 \pm 0.8$ & 0.006 \\
\hline & & ${ }^{*} P=0.02$ & ${ }^{\#} P=0.007$ & $P=0.12$ & ${ }^{\#} P=0.009$ & \\
\hline \multirow[t]{2}{*}{ FSL } & $11.89 \pm 1.8$ & $9.70 \pm 1.65$ & $13.5 \pm 3.2$ & $13.1 \pm 1.44$ & $11.1 \pm 2.5$ & 0.002 \\
\hline & & ${ }^{*} P=0.01$ & ${ }^{\#} P=0.001$ & $\# P=0.006$ & ${ }^{\#} P=0.003$ & \\
\hline \multirow[t]{2}{*}{ HSW } & $6.15 \pm 0.78$ & $7.00 \pm 0.88$ & $4.55 \pm 1.2$ & $6.15 \pm 0.78$ & $5.65 \pm 0.7$ & 0.001 \\
\hline & & ${ }^{*} P=0.004$ & $\# P<=0.001$ & $P=0.08$ & ${ }^{\#} P=0.002$ & \\
\hline \multirow[t]{2}{*}{ HSL } & $12.65 \pm 1.6$ & $10.1 \pm 1.46$ & $12.8 \pm 1.53$ & $13.5 \pm 1.24$ & $11.7 \pm 2.5$ & 0.001 \\
\hline & & ${ }^{*} P=0.02$ & ${ }^{\#} P=0.002$ & $\# P=0.001$ & ${ }^{\#} P=0.03$ & \\
\hline
\end{tabular}

$P$ value is calculated by ANOVA test, and is considered significant if $<0.05 . n=10$ in each group. Data was expressed as mean $\pm S D$

$O L$ overlap, FSW front stride width, FSL front stride length, HSW hind stride width, HSL hind stride length

*significant when compared to control group. "significant when compared to rotenone group

HSL $(\mathrm{p}=0.0009)$, and decreased the HSW and FSW $(\mathrm{p}=0.0008)$. L-dopa treatment improved the asymmetrical gait and caused an elongation in the stride length, and a decrease in OL in the rotenone-injected group $(\mathrm{p}=0.001)$, while it did not affect HSW $(\mathrm{p}=0.08)$ and FSW $(p=0.12)$. To sum, treadmill exercise alone and in combination with L-dopa treatment fully corrected the gait of rotenone-injected rats.

\section{Treadmill exercise, L-dopa, and their combination} prolonged the latency time to fall in the Rota-rod test

(Fig. 3)

There was a significant decrease in latency time to fall after 4 weeks of a daily injection of rotenone in rats compared to the control group $(\mathrm{p}=0.00008)$. Rats in all groups exhibited significant increases in the latency time to fall, in comparison to the rotenone-injected group $(\mathrm{p}=0.001)$. However, the L-dopa and the exercise/Ldopa-treated group showed a longer latency time than the exercise $\backslash$ rotenone group $(\mathrm{p}=0.02)$. Therefore, forced exercise, L-dopa treatment, and their combination prolonged the latency to fall in the Rota-rod test (Fig. 3).

Effects of treadmill exercise, L-dopa and their combination on tyrosine hydroxylase (TH) levels in the striatum

Rotenone administration in rats significantly reduced $\mathrm{TH}$ levels (to $40 \%$ of the control value) in the corpus

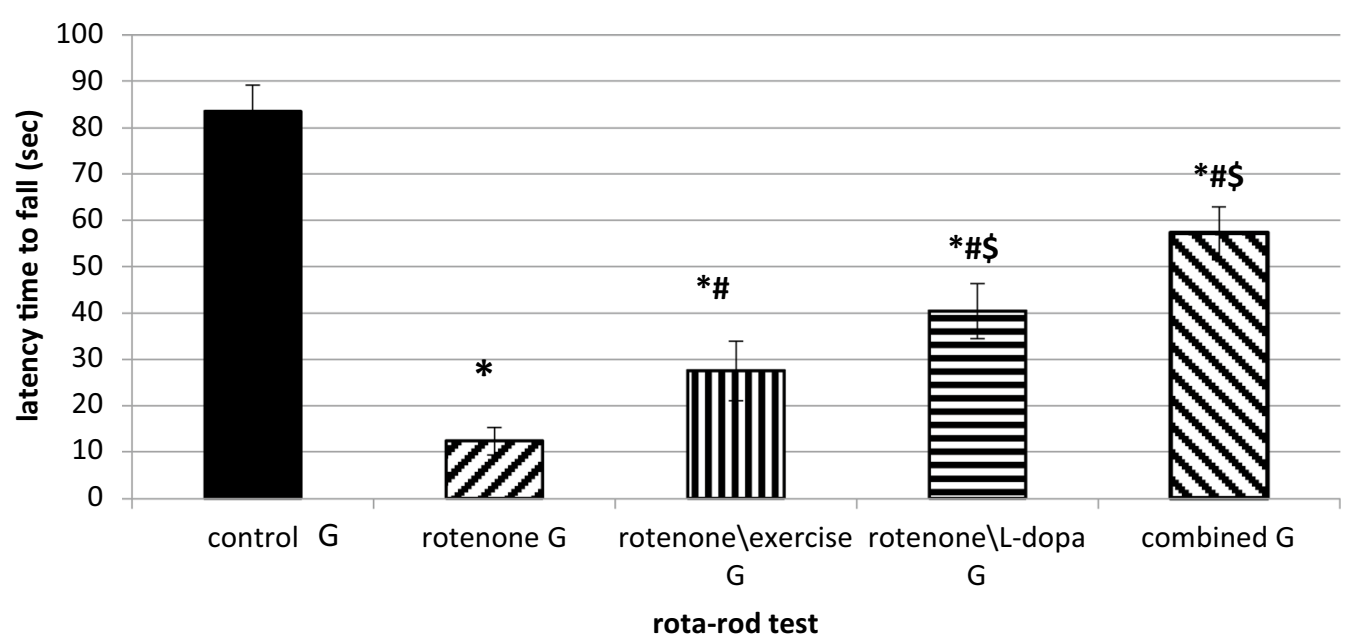

Fig. 3 Rota-rod test, the effect of exercise (4 weeks treadmill), L-dopa (6 mg $\backslash k g$ IP daily for 4 weeks), and their combination on rotenone treated rats ( 2 mg $\backslash k g$ SC for 4 weeks). P-value was calculated by ANOVA test and was considered significant if $<0.05$. $n=10$ in each group. * significant when compared to the control group. \#significant when compared to the rotenone-treated group. \$Significant when compared to rotenonelexercise G 
striatum when compared to the vehicle-injected group $(\mathrm{P}=0.00006)$. Whereas, forced exercise and their combined applications caused a significant increase in striatum $\mathrm{TH}$ levels which increased up to $62 \%$ and $78 \%$ of normal) when compared to the rotenoneinjected group $(\mathrm{P}=0.001)$. L-dopa alone didn't significantly increase the striatal $\mathrm{TH}$ level when compared to the rotenone group $(\mathrm{P}=0.17)$. Besides, the tyrosine hydroxylase level in the L-dopa \rotenone group was significantly lower than that of the exercise $\backslash$ rotenone and the combined group $(\mathrm{P}=0.09$, Fig. 4).

\section{Effects of treadmill exercise, L-dopa and their combination on Nrf2 expression in the striatum}

Rotenone caused a significant increase of Nrf2 $m R N A$ expression in the striatum of rats in comparison to the vehicle-injected group $(\mathrm{P}=0.02)$.

Forced exercise alone and in combination upregulated $N r f 2 m R N A$ expression in corpus striatum when compared to the rotenone-injected group $(\mathrm{P}=0.0009)$. However, treatment with L-dopa did not affect Nrf2 $m R N A$ expression $(\mathrm{P}=0.62)$. Moreover, Nrf2 mRNA expression was lower in the L-dopa|rotenone group compared to the exercise $\backslash$ rotenone group $(\mathrm{P}=0.00)$. Interestingly, the combination between forced exercised and L-dopa treatment showed a significant increase in Nrf2 mRNA expression in comparison to the exercise $\backslash$ rotenone group $(\mathrm{P}=0.03)$ and $\mathrm{L}$-dopa|rotenone group $(\mathrm{P}=0.001)$.
This study showed that the administration of rotenone increased Nrf2 expression in the corpus striatum, such upregulation was augmented by forced exercise, dramatically increased by the combination of treatment of L-dopa and forced exercise, but was not affected by single treatment of L-dopa (Fig. 5a).

Effects of treadmill exercise, L-dopa and their combination on target genes of Nrf2 in the striatum

Rotenone significantly increased expression of NQO1 in the rotenone group compared to control $(\mathrm{P}=0.0009)$ as shown in Fig. 5b. Exercise produced a significant increase in NQO1 mRNA expression level when compared to the rotenone group $(\mathrm{P}=0.001)$. However, the $\mathrm{L}$-dopa treatment reduced NQO1 mRNA expression in the rotenone-injected group $(P=0.001)$. Whereas when exercise performed with L-dopa treatment did not change NQO1 $m R N A$ expression compared to the rotenone group $(\mathrm{P}=0.49)$, but decreased NQO1 mRNA expression when compared to the exercise $\backslash$ rotenone group $(\mathrm{P}=0.003)$. Additionally, there was a significant increase in NQO1 expression in the exercise $\backslash \mathrm{L}$-dopa $\backslash$ rotenone group compared to the $\mathrm{L}$-dopa $\backslash$ rotenone group $(\mathrm{P}=0.001)$ (Fig. 5b).

Consistently, treadmill exercise caused a significant increase in TFAM mRNA expression after injection of rotenone and when practiced in combination with L-dopa treatment compared to rotenone group $(\mathrm{P}<0.001)$ and $\mathrm{L}$-dopa $\mid$ rotenone $(\mathrm{P}=0.0009$ and $=0.01$,

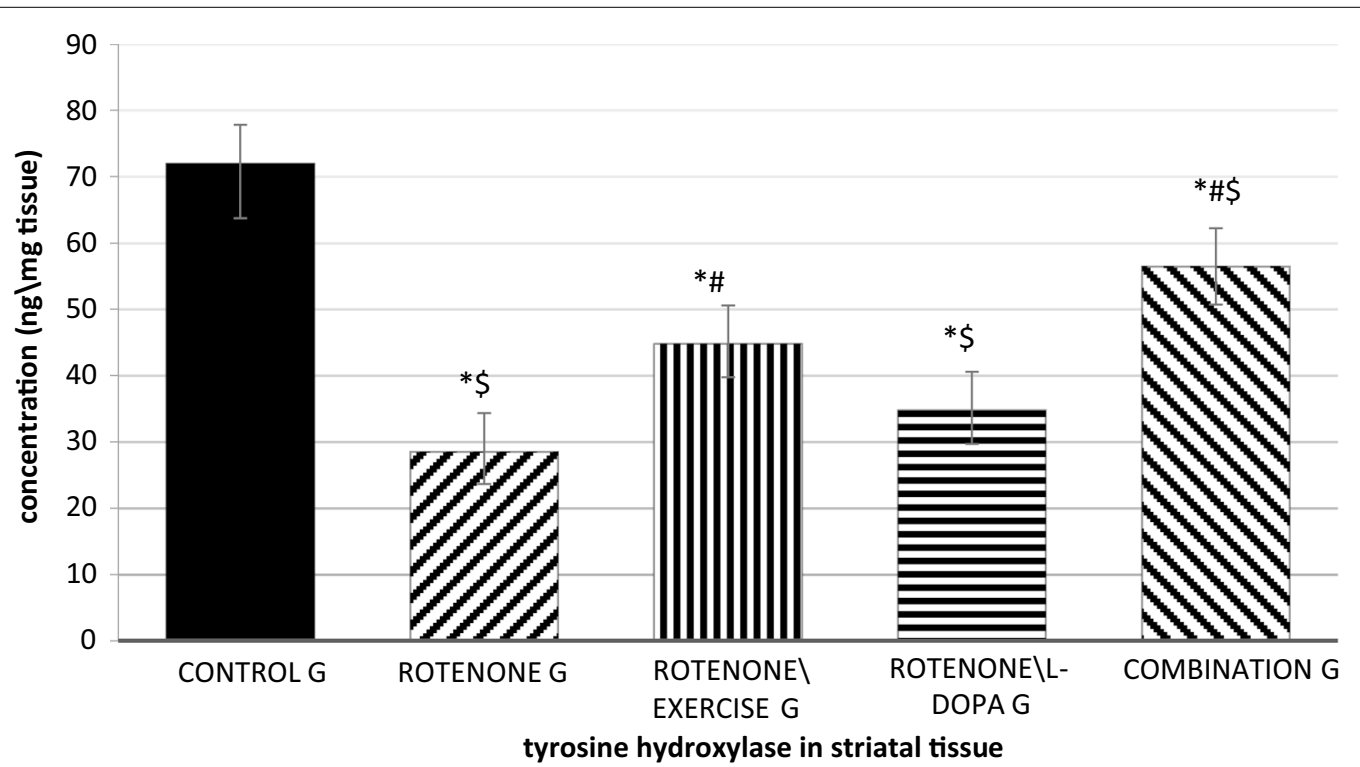

Fig. 4 Striatal tyrosine hydroxylase measured by ELISA, effect of exercise ( 4 weeks treadmill), L-dopa (6 mg $\backslash k g$, IP daily for 4 weeks), and their combination on tyrosine hydroxylase level in rotenone-treated rats ( 4 weeks, $2 \mathrm{mg} \backslash \mathrm{kg}, \mathrm{SC}$ ). P-value is obtained by ANOVA and is considered significant if $<0.05$. *significant in comparison to the control group, "significant when compared to the rotenone group, $\$$ significant when compared to the rotenone exercise group. $n=10$ in each group 
(See figure on next page.)

Fig. 5 Expression levels of genes by PCR in the corpus striatum, effect of exercise (4 weeks treadmill), L-dopa (6 mg $\backslash k g$ IP daily for 4 weeks), and their combination on rotenone treated rats ( $2 \mathrm{mg} \backslash \mathrm{kg}$ SC for 4 weeks). a Nrf2 gene, $\mathbf{b}$ expression level of NADPH dehydrogenase (NQO1) mRNA, and c expression level of TFAM mRNA, P-value is calculated by ANOVA test, and is considered significant if $<0.05 . n=10$ rats in each group. ${ }^{*}$ Significant when compared to control G. " significant when compared to the rotenone group. ${ }^{\$}$ Significant when compared to the rotenonelexercise group

successively). Similar to NQO1 expression, L-dopa treatment did not affect TFAM $m R N A$ expression in the rotenone-injected group $(\mathrm{P}=0.73)$. There was a significant increase in TFAM $m R N A$ expression in the combination group when compared to the exercise $\mid$ rotenone group $(\mathrm{P}=0.05)$, (Fig. 5c).

Overall, our results demonstrated that 4 weeks of daily treatment with rotenone increased Nrf2-related genes, NQO1 and TFAM, expression in the corpus striatum. Such expression was enhanced by forced exercise and was not affected by a single treatment of L-dopa (Fig. 5b, c).

\section{Discussion}

Parkinson's disease (PD) is a common neurodegenerative disease, about $1 \%$ above the age of 65 years suffer from. In PD, there is a progressive degeneration of dopaminergic neurons of the substantia nigra of the midbrain [22]. This results in the characteristic motor impairment and the extra motor manifestation of the disease. Rotenone is known to induce PD in rats by targeting dopaminergic neurons [23]. It acts by inhibiting complex I of the mitochondrial electron transport chain and causing accumulation of reactive oxygen species (ROS) and subsequently, cell damage. Age-related mitochondrial dysfunction and oxidative stress have been strongly involved in the pathophysiology of PD [24, 25].

In this study, rotenone $2 \mathrm{mg} \backslash \mathrm{kg} \backslash$ day was injected by the subcutaneous route for 4 weeks to induce rotenone-Parkinson's disease rat model. The rotenone-treated group, showed a significant decrease in exploration and locomotion as regards to the open field test, gait impairment; (asymmetrical foot pattern, shortened stride length, and widened base), a significant decline in motor coordination was observed by shortened latency time on Rotarod. Cognitive function impairment of PD also existed; as a significant decrease in novel object preference in the short-term memory test. Tyrosine hydroxylase levels in the striatum significantly decreased in rotenone treated rats. Similar to our study, Vijayalakshmi et al. [26] and Valdez et al. [27] reported a significant decrease in locomotion in the Open field test in rotenone-treated Wister rats. von Wrangel et al. [28], and Cannon et al. [12] reported that rotenone-treated rats showed significant impairment in Rota-rod and significant decline in tyrosine hydroxylase in the striatum. As regard footprint test, the results of this study were in line with Madiha et al. [29] their data showed significantly impaired walking pattern and shortened stride length in rotenone-treated rats.

Treadmill exercise significantly increased exploration and locomotion in rotenone-treated rats. Treadmill exercise corrected the gait impairment in rotenonetreated rats; the asymmetrical patterns were corrected by a significant reduction in overlap, accompanied by a significant increase in stride length and a significant decrease in stride width. Treadmill exercise significantly improved short-term memory novel object recognition in the rotenone-treated group. Tyrosine hydroxylase levels significantly increased in the brain after treadmill exercise. Exercise also improved motor coordination as it increased latency time to fall on Rota-rod significantly. The beneficial effects of the treadmill and other means of exercise in improving motor coordination (prolong latency time to fall on Rota-rod) were also reported by Shin et al. and Lee et al. [30, 31], in the rotenone model of PD. In line with our study, Chen et al. [32] reported a significant improvement of the Rota-rod test in addition to a significant gait improvement (improved overlap, stride length, and base width) with treadmill exercise but in 6-OHDA model PD.

When L-dopa was administrated in rotenone-treated rats, a significant improvement regarding exploration and locomotion was found. Motor co-ordination significantly improved ever more than exercise alone. The gait showed significant partial improvement, the asymmetrical pattern was significantly corrected, and the stride length significantly increased, meanwhile, short-term memory did not significantly improve. Tyrosine hydroxylase levels did not significantly increase in the brain. Our results agree with Allam et al. [33] who found a significant increase in locomotor activity and exploration with L-dopa treatment of rotenone-treated rats in the open field test, and Sgroi et al. [34] who reported a significant increase in locomotion and motor co-ordination with $8 \mathrm{mg} \backslash \mathrm{kg}$ L-dopa treatment for ten days in 6-OHDA model of PD.

When L-dopa treatment was accompanied by treadmill exercise, there was a significant increase in exploration and locomotion behavior in the open field. A significant increase in the latency time of the Rota-rod test was found indicating improved motor coordination. There was a significant gait improvement with L-dopa and exercise co-treatment, the asymmetrical pattern was fully 

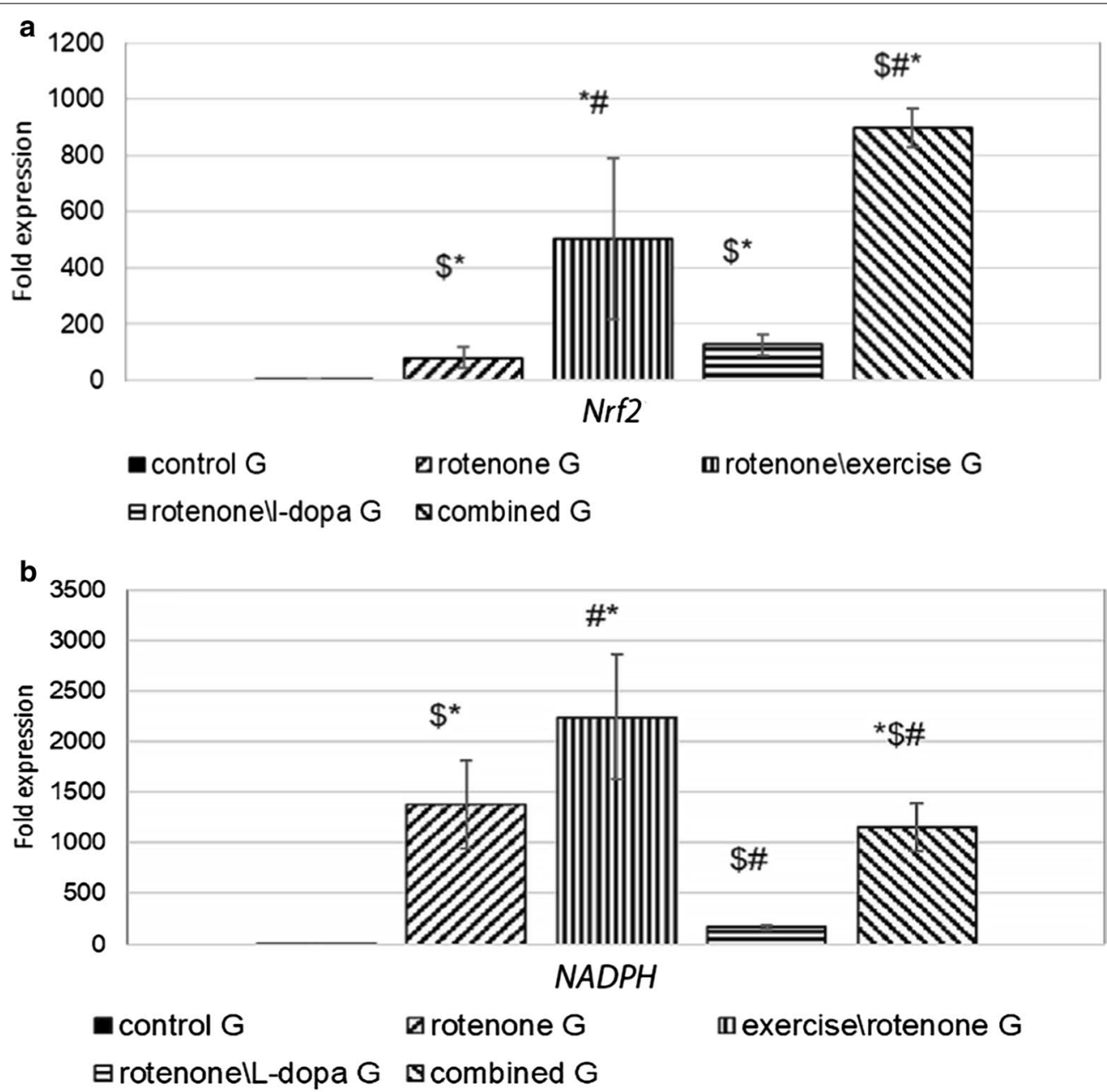

c

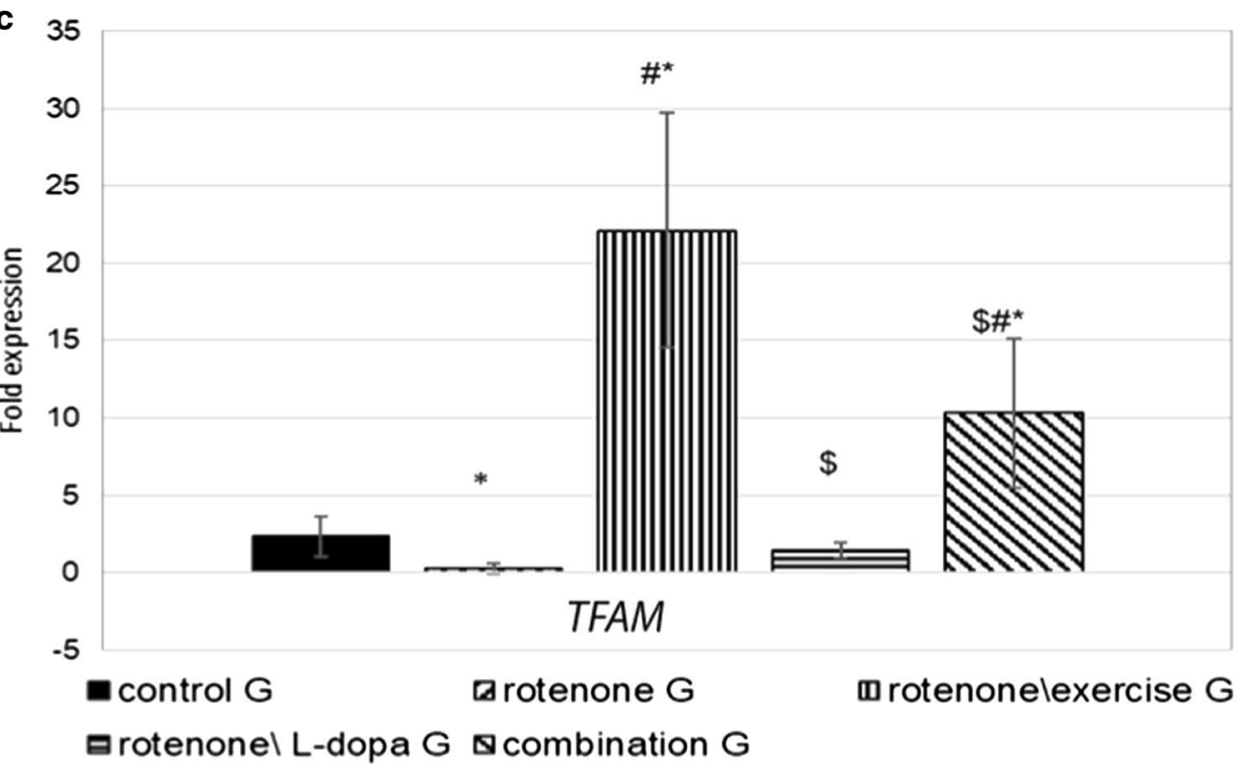


corrected, with a significant increase in stride length and a significant decrease in stride width. Short-term memory significantly improved. Tyrosine hydroxylase levels in the brain were significantly increased.

In our study, we investigated some genes of the Nrf2$A R E$ pathway as a possible mechanism involved in the treadmill exercise effects on the brain. Exercise causes an increase in $\mathrm{O} 2$ consumption with an increase in ROS production, especially $\mathrm{H} 2 \mathrm{O} 2$. Oxidative stress leads to inhibition of KEAP-1, dissociation of Nrf2 from KEAP1 in the cytoplasm, migrates into the nucleus, and activates the Nrf2-ARE [35]. Nrf2 activates anti-oxidant gene expression with increased productions of detoxifying enzymes: Heme oxygenase, and NADPH quinone oxidoreductase (NQO.1). Activation of Nrf2 together with $P C G 1 \alpha$, which also is activated by exercise, caused an increase in mitochondrial transcription factor A (TFAM) expression in the striatum. TFAM is a nuclear factor that controls the replication of mitochondrial DNA (mt DNA). The upregulation of TFAM increases the number of copies and packaging of mtDNA. Also, adequate levels of TFAM are required to prevent mtDNA release into the cytoplasm and initiate an inflammatory response [11].

This study measured the rate of expression of $\mathrm{Nrf2}$, TFAM, and Nqo.1 in the striatum of rotenone-treated rats. Rotenone downregulated expression of the TFAM in the rotenone group while upregulated $\mathrm{Nrf2}$ and $\mathrm{Nqo1}$ in comparison to the control rats. Treadmill exercise showed a significant increase in Nrf2, TFAM, and NQO.1 in the striatum in the exercise $\backslash$ rotenone group in comparison to control and rotenone groups. L-dopa|rotenone group showed an insignificant change in the expression of these genes. However, the exercised $\backslash \mathrm{L}$-dopa|rotenone group, showed a significant increase in Nrf2, TFAM, and Nqo.1 expression, when compared to both control and rotenone group.

Whether rotenone increases or decreases the expression of Nrf2 and NQO1 is a matter of debate. Many studies [36] found that rotenone in in-vivo and in-vitro studies downregulated the expression of these genes and enhanced apoptosis of the neurons in the nigrostriatal tissue which was reversed by administration of danshensu herbal extract. Similarly, Cui et al. [37] found decreased expression of NRF2 and NQO1 proteins measured by western blotting in rotenone treated rats which were corrected with pretreatment with curcumin. On the contrary, Wei et al. [38] found that rotenone increased NRF2 and NQO1 expression in the striatum which was further enhanced by ellagic acid. They measured the NRF2 protein in the cytoplasm and in the nucleus of the cell indicating that the expression of these transcription factors was increased in the nucleus.
As regard expression of TFAM, this is the first study which investigated its expression in rotenone-treated rats, Rotenone downregulated TFAM expression which may underlie the instability in the mtDNA and consequent damage of the dopaminergic neuron. This is evidenced by the decreased level of tyrosine hydroxylase measured in the striatum. Noteworthy, Chen et al. [39] in their study on post mortem human parkinsonian patients found that expression of TFAM in substantia nigra is lower and their mtDNA is less stable in comparison to age-matched elderly control subjects.

As regards our study results, treadmill exercise activated the Nrf2 pathway in the striatum of the rotenone-treated rat. This activation could be one of the mechanisms involved in treadmill exercise beneficial effects on the rotenone-treated model of PD. Few studies which measured TFAM expression in animal models e.g. Aguiar et al. [40] reported that exercise significantly increased Nrf2 and TFAM in the striatum of 6-OHDA hemiparkinsonism. Other studies reported TFAM activation with exercise in different pathological conditions other than parkinsonism. For instance, Lashgarie et al. [11] reported that treadmill exercise increased TFAM expression in the heart of nicotine sensitized rats, which attenuated mitochondrial-mediated damage in the myocardium induced by nicotine.

\section{Conclusion}

In this study, treadmill exercise increased tyrosine hydroxylase and activated the Nrf2 pathway and some of its associated genes however L-dopa could not. Where L-dopa corrected locomotion, exploration, and motor coordination but failed to improve short-term memory and only partially corrected the gait of rotenone-treated rats. When treadmill exercise was combined with L-dopa, all the behavioral motor and non-motor aspects of PD were corrected.

\section{Recommendation}

Exercise is highly recommended and is a mandatory approach for the treatment of parkinsonism in humans. Further studies are needed to explore the importance of expression of the TFAM gene as part of the Nrf2 pathway in protecting against mitochondrial induced oxidative damage.

\section{Supplementary information}

Supplementary information accompanies this paper at https://doi. org/10.1186/s12993-020-00171-9. 
Additional file1: Figure S1. The effects of exercise on serum levels of CPK and LDH in control groups, ${ }^{*}$ if the differences were significantly different from the control group.

\section{Abbreviations}

ARE: Antioxidant response elements; DA: Dopamine; NQO1: NAD(P) H quinone oxidoreductase 1: NAD(P)H dehydrogenase; Nrf2: Nuclear factor erythroid 2 (NFE2)-related factor 2; PA: Physical activity; PGC1a: Peroxisome-proliferatoractivated receptor- $\gamma$ coactivator-1 a; ROS: Reactive oxygen species; TFAM: Mitochondrial transcriptional factor A; OL: Overlap; FSL: Forward stride length; FSW: Forward stride width; HSL: Hind stride length; HSW: Hind stride width.

\section{Acknowledgements}

The authors would like to thank the staff of the central laboratory in Sohag Medical Faculty for their cooperation all over the period of practical work.

\section{Authors' contributions}

AA selected the point of research, MM and DM equally contributed to the practical part of the study, IR collected the data and shared in the analysis of the behavioral tests, all authors shared in the writing of the research with final revision from OG and AA. All authors read and approved the final manuscript.

\section{Funding}

The authors declare that there is no special funding taken for this research.

\section{Availability of data and materials}

The datasets used and/or analyzed during the current study are available from the corresponding author on request.

\section{Ethics approval and consent to participate}

The study was approved by the Sohag University research Ethics Committee considering care and use of laboratory animals (permission number: SOH-IACUC-17050301).

\section{Consent for publication}

All authors accept publication in this journal.

\section{Competing interests}

The authors declare that they have no competing interests.

\section{Author details}

1 Department of Physiology, Faculty of Medicine, Sohag University, Sohag 82524, Egypt. ${ }^{2}$ Department of Animal Behavior and Husbandry (Genetics, Breeding, and Production), Faculty of Veterinary Medicine, Sohag University, Sohag 82524, Egypt. ${ }^{3}$ Department of Physiology, Faculty of Medicine, Assiut University, Assiut 71526, Egypt. ${ }^{4}$ Department of Husbandry and Development of Animal Wealth, Faculty of Veterinary Medicine, Menofia University, Shebin Alkom, Menofia 32511, Egypt.

Received: 3 April 2020 Accepted: 16 October 2020

Published online: 06 November 2020

\section{References}

1. Kabuto H, Yamanashi TT. Effects of zingerone [4-(4-hydroxy-3methoxyphenyl)-2-butanone] and eugenol [2-methoxy-4-(2-propenyl) phenol] on the pathological progress in the 6-hydroxydopamineinduced Parkinson's disease mouse model. Neurochem Res. 2011;36(12):2244-9.

2. Dasuri K, Zhang L, Keller JN. Oxidative stress, neurodegeneration, and the balance of protein degradation and protein synthesis. Free Radical Biol Med. 2013;62:170-85.

3. Li N, Ragheb K, Lawler G, Sturgis J, Rajwa B, Melendez JA, et al. Mitochondrial complex I inhibitor rotenone induces apoptosis through enhancing mitochondrial reactive oxygen species production. J Biol Chem. 2003;278(10):8516-25.

4. Zorov DB, Juhaszova M, Sollott SJ. Mitochondrial Reactive Oxygen Species (ROS) and ROS-Induced ROS Release. Physiol Rev. 2014;94(3):909-50.
5. Ferris CF, Marella M, Smerkers B, Barchet TM, Gershman B, Matsuno-Yagi A et al. A phenotypic model recapitulating the neuropathology of Parkinson's disease. Brain Behav. 2013;3(4):351-66.

6. Bezard E, Yue Z, Kirik D, Spillantini MG. Animal models of Parkinson's disease: limits and relevance to neuroprotection studies. Movement Disord. 2013;28(1):61-70.

7. Lee NY, Lee DK, Song HS. Effect of virtual reality dance exercise on the balance, activities of daily living, and depressive disorder status of Parkinson's disease patients. J Phys Ther Sci. 2015;27(1):145-7.

8. Um HS, Kang EB, Leem YH, Cho IH, Yang CH, Chae KR, et al. Exercise training acts as a therapeutic strategy for reduction of the pathogenic phenotypes for Alzheimer's disease in an NSE/APPsw-transgenic model. Int J Mol Med. 2008;22(4):529-39.

9. LiT, He S, Liu S, Kong Z, Wang J, Zhang Y. Effects of different exercise durations on Keap1-Nrf2-ARE pathway activation in mouse skeletal muscle. Free Radical Res. 2015;49(10):1269-74.

10. Hinson VK, Goetz CG, Leurgans S, Fan W, Nguyen T, Hsu A. Reducing dosing frequency of carbidopa/levodopa: double-blind crossover study comparing twice-daily bilayer formulation of carbidopa/levodopa (IPX054) versus 4 daily doses of standard carbidopa/levodopa in stable Parkinson disease patients. Clin Neuropharmacol. 2009;32(4):189-92.

11. Lashgari AA, Azarbayjani M-A, Peeri M, Nasehi M. The Effect of ShortTerm Treadmill Exercise on the Expression Level of TFAM in the Heart of Nicotine-Sensitized Rats. Archives of Advances in Biosciences. 2020;11(1)

12. Cannon JR, Tapias V, Na HM, Honick AS, Drolet RE, Greenamyre JT. A highly reproducible rotenone model of Parkinson's disease. Neurobiol Dis. 2009;34(2):279-90.

13. Shin JH, Kang KW, Kim JH, Chin JY, Kim NY, Park SH, et al. Treadmill exercise-induced E/e' elevation as a predictor of cardiovascular event in end-stage renal disease on peritoneal dialysis. Korean J Intern Med. 2016.

14. Walsh RN, Cummins RA. The Open-Field Test: a critical review. Psychol Bull. 1976;83(3):482-504.

15. Ennaceur A, Delacour J. A new one-trial test for neurobiological studies of memory in rats. 1: Behavioral data. Behav Brain Res. 1988;31(1):47-59.

16. Mahmoud ME, Fereig R, Nishikawa Y. Involvement of Host Defense Mechanisms against Toxoplasma gondii Infection in Anhedonic and Despair-Like Behaviors in Mice. Infection and immunity. 2017;85(4).

17. Dunham NW, Miya TS. A note on a simple apparatus for detecting neurological deficit in rats and mice. J Am Pharm Assoc . 1957;46(3):208-9.

18. Chiu K, Lau WM, Lau HT, So K-F, Chang RC-C. Micro-dissection of the rat brain for RNA or protein extraction from specific brain region. Journal of visualized experiments: JoVE. 2007(7).

19. Yamashita Y, Ueyama T, Nishi T, Yamamoto Y, Kawakoshi A, Sunami S, et al. Nrf2-inducing anti-oxidation stress response in the rat liver-new beneficial effect of lansoprazole. PLoS One. 2014;9(5).

20. Santos JM, Kowluru RA. Impaired transport of mitochondrial transcription factor A (TFAM) and the metabolic memory phenomenon associated with the progression of diabetic retinopathy. Diab Metab Res Rev. 2013;29(3):204-13.

21. Jeong KJ, Quan H-Y, Jo HK, Kim GW, Chung SH. Effects of eugenol on hepatic glucose production and AMPK signaling pathway in hepatocytes and C57BL/6J mice. Fitoterapia. 2014;93:150-62.

22. Hughes AJ, Daniel SE, Kilford L, Lees AJ. Accuracy of clinical diagnosis of idiopathic Parkinson's disease: a clinico-pathological study of 100 cases. J Neurol Neurosurg Psychiatry. 1992;55(3):181-4

23. Betarbet R, Sherer TB, MacKenzie G, Garcia-Osuna M, Panov AV, Greenamyre JT. Chronic systemic pesticide exposure reproduces features of Parkinson's disease. Nat Neurosci. 2000;3(12):1301-6.

24. Jenner P. Oxidative stress in Parkinson's disease. Annals Neurol. 2003:53(Suppl3):S26-36 (Discussion S-8).

25. Tan YF, O'Toole N, Taylor NL, Millar AH. Divalent metal ions in plant mitochondria and their role in interactions with proteins and oxidative stress-induced damage to respiratory function. Plant Physiol. 2010;152(2):747-61.

26. KS, KV, Selvaraj R. Behavioral studies of wistar rats in rotenone induced model of parkinson's disease. Int J Pharm Pharmaceutical Sci. 2017:9:159.

27. Valdez LB, Zaobornyj T, Bandez MJ, Lopez-Cepero JM, Boveris A, Navarro A. Complex I syndrome in striatum and frontal cortex in a rat model of Parkinson disease. Free Radical Biol Med. 2019;135:274-82. 
28. von Wrangel C, Schwabe K, John N, Krauss JK, Alam M. The rotenoneinduced rat model of Parkinson's disease: behavioral and electrophysiological findings. Behav Brain Res. 2015;279:52-61.

29. Madiha S, Tabassum S, Batool Z, Liaquat L, Sadir S, Shahzad S, et al. Assessment of gait dynamics in rotenone-induced rat model of Parkinson's disease by footprint method. Pakistan J Pharm Sci. 2017;30(3):943-8.

30. Shin MS, Kim TW, Lee JM, Ji ES, Lim BV. Treadmill exercise alleviates nigrostriatal dopaminergic loss of neurons and fibers in rotenone-induced Parkinson rats. J Exercise Rehab. 2017;13(1):30-5.

31. Lee JM, Kim TW, Park SS, Han JH, Shin MS, Lim BV, et al. Treadmill exercise improves motor function by suppressing purkinje cell loss in parkinson disease rats. Int Neuro J. 2018;22(Suppl 3):S147-55.

32. Chen $\mathrm{CH}$, Huang $\mathrm{TH}$, Cheng $\mathrm{TL}$, Chang $\mathrm{CF}$, Wang $\mathrm{CZ}$, Wu MH, et al. Exercise training ameliorates glucosamine-induced insulin resistance in ovariectomized rats. Menopause. 2017;24(6):617-23.

33. Alam M, Schmidt W. Rotenone destroys dopaminergic neurons and induces parkinsonian symptoms in rats. Behav Brain Res. 2002;136(1):317-24

34. Sgroi S, Kaelin-Lang A, Capper-Loup C. Spontaneous locomotor activity and L-DOPA-induced dyskinesia are not linked in 6-OHDA parkinsonian rats. Front Behav Neurosci. 2014;8:331.

35. Vargas-Mendoza N, Morales-González Á, Madrigal-Santillán EO, MadrigalBujaidar E, Álvarez-González I, García-Melo LF, et al. Antioxidant and adaptative response mediated by Nrf2 during physical exercise. Antioxidants. 2019;8(6):196
36. Wang T, Li C, Han B, Wang Z, Meng X, Zhang L, et al. Neuroprotective effects of Danshensu on rotenone-induced Parkinson's disease models in vitro and in vivo. BMC Compl Med Therapies. 2020;20(1):20.

37. Cui Q, Li X, Zhu H. Curcumin ameliorates dopaminergic neuronal oxidative damage via activation of the Akt/Nrf2 pathway. Mol Med Rep. 2016;13(2):1381-8.

38. Wei Y-Z, Zhu G-F, Zheng C-Q, Li J-J, Sheng S, Li D-D, et al. Ellagic acid protects from rotenone-induced dopaminergic neuronal damage via activation of Nrf2 signaling in astroglia. 2020.

39. Chen C, Vincent AE, Blain AP, Smith AL, Turnbull DM, Reeve AK. Investigation of mitochondrial biogenesis defects in single substantia nigra neurons using post-mortem human tissues. Neurobiol Dis. 2020;134:104631.

40. Aguiar AS, Duzzioni M, Remor AP, Tristao FSM, Matheus FC, RaismanVozari R, et al. Moderate-intensity physical exercise protects against experimental 6-hydroxydopamine-induced hemiparkinsonism through Nrf2-antioxidant response element pathway. Neurochem Res. 2016;41(1-2):64-72.

\section{Publisher's Note}

Springer Nature remains neutral with regard to jurisdictional claims in published maps and institutional affiliations.
Ready to submit your research? Choose BMC and benefit from:

- fast, convenient online submission

- thorough peer review by experienced researchers in your field

- rapid publication on acceptance

- support for research data, including large and complex data types

- gold Open Access which fosters wider collaboration and increased citations

- maximum visibility for your research: over 100M website views per year

At BMC, research is always in progress.

Learn more biomedcentral.com/submissions 